\title{
A Case of Intractable Tracheitis Treated by Heat-Moisture Exchangers in a Total Laryngectomized Patient
}

\author{
Beom Mo Koo (D), Seong Kyu Moon (D), and Seung Woo Kim (D) \\ Department of Otolaryngology-Head and Neck Surgery, Veterans Health Service Medical Center, Seoul, Korea
}

\section{열가습 여과기로 치료한 후두전적출 환자의 난치성 기관염 1 예}

구범모, 문성규, 김승우

중앙보훈병원 이비인후과

The tracheostomy directs external air into the airway tract. This process causes mucosal dryness, irritation and inflammation in the tracheo-bronchial tree. In order to prevent such problems, several methods are applied; ointment application, humidification and careful suction etc. The heat-moisture exchanger (HME) is commercially sold device that assists heating and humidification of the inhaled air. The authors experienced successful treatment outcome of intractable tracheitis caused by repetitive and vigorous intra-tracheal suction by applying HME in a total laryngectomized patient. We report an interesting and didactic case with a brief literature review.

Keywords Tracheitis; Total laryngectomy; Heat and moisture exchangers.

\section{서 론}

후두전적출술 환자는 외부의 차갑고 건조한 공기가 바로 기도로 흡입되어, 기관 및 기관지의 점막상피세포에 직접적인 자극을 가하게 된다. 이러한 일련의 과정은 기도 점 막의 건조, 점액섬모 청소율의 감소 및 기관상피세포의 손상 등으로 이어져 기도 감염의 주요 위험 인자로 작용할 수 있다. ${ }^{1)}$ 이런 현상을 예방하기 위하여 보존적 치료로 기관공 주변의 연고 도포, 가습 및 기도 분비물의 흡인 등을 시행하게 된다. 최근에는 다양한 종 류의 열가습 여과기(heat and moisture exchangers, HMEs)가 소개되어, 이를 착용하면 들숨이 가습 및 가온되어, 위에서 기술한 합병증의 예방에 크게 도움이 될 수 있다. ${ }^{2}$

내원 2년 전에 후두전적출술을 시행받은 78세 남자가 심한 호흡곤란으로 응급실로 내원하였다. 저자들은 HMEs에 주된 치료 반응을 보인 '난치성 기관염'을 치험하여 문 헌고찰과 함께 보고하고자 한다.

\author{
Received September 16, 2020 \\ Revised October 27, 2020 \\ Accepted November 9, 2020

\section{Corresponding Author} \\ Seung Woo Kim, MD \\ Department of Otolaryngology-Head \\ and Neck Surgery, \\ Veterans Health Service Medical Center, \\ 53 Jinhwangdo-ro 61-gil, Gangdong-gu, \\ Seoul 05368, Korea \\ Tel +82-2-2225-1384 \\ Fax+82-2-2225-1385 \\ E-mail entzzang1020@daum.net
}

\section{ORCID iDs}

Beom Mo Koo (D)

https://orcid.org/0000-0002-2597-1204

Seong Kyu Moon (D)

https://orcid.org/0000-0001-6690-2769

Seung Woo Kim (D)

https://orcid.org/0000-0002-7931-6977

$$
\begin{aligned}
& \text { This is an Open Access article distributed } \\
& \text { under the terms of the Creative } \\
& \text { Commons Attribution Non-Commercial } \\
& \text { License (https://creativecommons.org/ } \\
& \text { licenses/by-nc/4.0) which permits } \\
& \text { unrestricted non-commercial use, } \\
& \text { distribution, and reproduction in any } \\
& \text { medium, provided the original work is } \\
& \text { properly cited. }
\end{aligned}
$$




\section{증 례}

78세 남자 환자가 내원 2일 전부터 급격히 악화된 심한 호 흡곤란을 주소로 응급실로 내원하였다. 2년 전 후두전적출 술을 시행받고 재발 없이 추적 관찰 중이었으며, 당뇨, 고혈 압 및 전립선암 등의 병력이 있었다. 환자는 넬라톤관으로 만 족할 때까지 기관 내를 자가흡인하는 습관이 있었다. 내원 직 후 시행한 후두 내시경 검사에서 기관 내부가 혈병 및 가피 등으로 $90 \%$ 이상 폐쇄되어 겸자와 흡입기(suction) 등으로 이를 모두 제거하고, 증상은 바로 호전되었다. 그러나 6시간 후 같은 증상이 재발하여 동일한 방법으로 가피를 제거하였 으나, 기관 점막에 광범위한 미란과 출혈 등의 소견이 관찰되 었다(Fig. 1A and B). 혈액 검사에서 백혈구는 $14.58 \times 10^{3} / \mu \mathrm{L}$ (참고값: 4 10), 적혈구 침강 속도는 $42 \mathrm{~mm} / \mathrm{hr}$ (참고값: 0 30) 및 C-반응 단백질은 $110 \mathrm{mg} / \mathrm{L}$ (참고값: 0 3) 등으로 증가하였고, 동맥혈 검사에서는 산소 포화도가 $92.4 \%$, 산소 분압이 $78.2 \mathrm{~mm} \mathrm{Hg}$ (참고값: 83 108) 및 이산화탄소 분압이 $51.5 \mathrm{~mm} \mathrm{Hg}$ (참고값: 35 48) 등의 저산소증 소견이었다. 객 담 배양 검사에서 메티실린 내성 황색포도상구균이 동정되 어 항생제는 반코마이신과 메로페넴 등을 사용하였고, 기관 습윤을 위하여 생리 식염수 및 국소 기관지 확장제 등의 흡 입 치료를 1 일 4회 시행하였다. 병변의 범위 평가와 호흡곤란 의 다른 원인 질환의 감별을 위해서 시행한 흥부 전산화단
층촬영에서는 기관에서 양측 주 기관지벽까지 조영증강되 고, 점막이 비후돼 있는 소견이 관찰되었다(Fig. 2A and B). 이러한 임상 소견 등을 종합해서 후두전적출 이후에 잘못된 흡입관 사용으로 병발된 기관염으로 진단하였다. 혈병 및 가 피 등의 물리적 제거로 일시적 증상 호전은 가능하지만, 가피 의 제거 시 필연적으로 점막 손상이 일어나서, 동일한 염증 소견이 반복되었다.

재원 2일째, 호흡기 내과에서 시행한 기관지 내시경 소견에 서 기관 및 양측 주 기관지를 막고 있는 혈병을 제거하고, 가 습된 산소를 지속적으로 공급하기 위해 인공호흡기를 적용하 였다. 24시간 후 상태가 호전되어, T자관으로 산소를 공급하 였으나, 다음날 시행한 후두 내시경에서 다시 이전과 유사한 소견이 관찰되어, 열가습 여과기(HMEs)의 한 종류인 '트라코 가습보조기 III ${ }^{\circledR}$ (Tracoe humid assist III ${ }^{\circledR}$, Tracoe, NeiderOlm, Germany)를 기관절개관에 연결하였다(Fig. 3). 이 기 구를 착용하고 24 시간 후 시행한 내시경 소견에서 기관 점막 은 혈병 및 가피 등이 현저히 감소하고, 광범위한 점막 미란도 한층 호전되는 소견 등이 관찰되었다(Fig. $1 \mathrm{C}$ and D). 이때 시행한 염증 지표 혈액 검사와 동맥혈 검사 등도 정상 범위를 보였다. HMEs 착용 3주 후에는 점막에 경한 염증 소견만 있 고, 호흡기 증상이 없는 상태에서, 기도 흡인의 올바른 요령과 $\mathrm{HMEs}$ 를 정확하게 거치하는 방법 등을 교육받고 퇴원하였다. 3개월 이후에 시행한 후두 내시경에서 기관은 염증 소견은
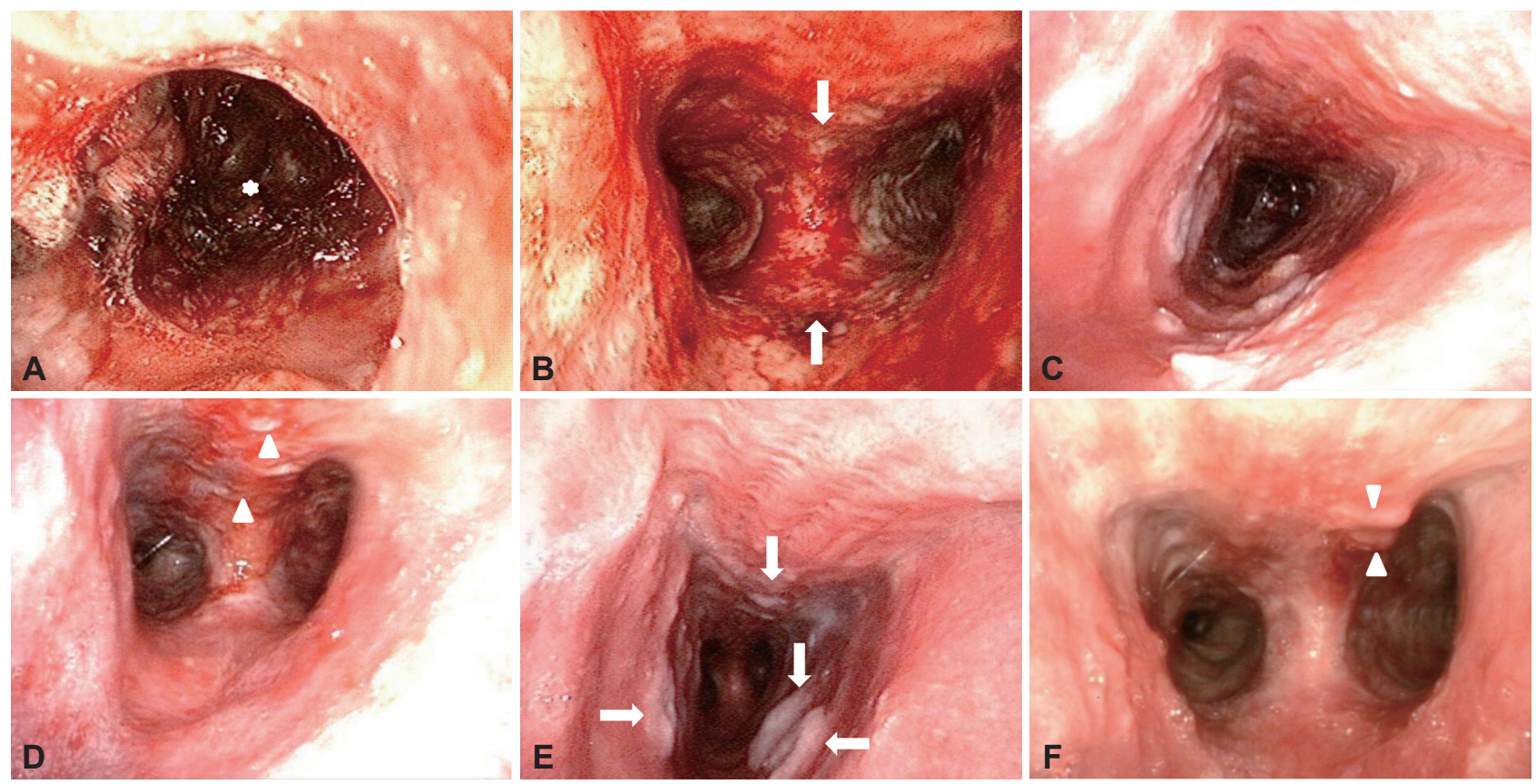

Fig. 1. Flexible laryngoscopic findings. These pictures show a series of treatment processes on trachea and carina. At first visiting to emergency medicine, it shows near totally obstructed airway tract by crusts (asterisk) (A). After removal of crusts, it shows severe mucosal erosions and bleeding (arrows) (B). At hospital day fourteen, it shows much improved lesion with favorable healing process on trachea (C), but some mucosal erosion is still observed on peri-carinal area (arrowheads) (D). Three months later, there was no abnormal finding except some thickened mucosa (arrows) (E), (arrowheads) $(F)$. 

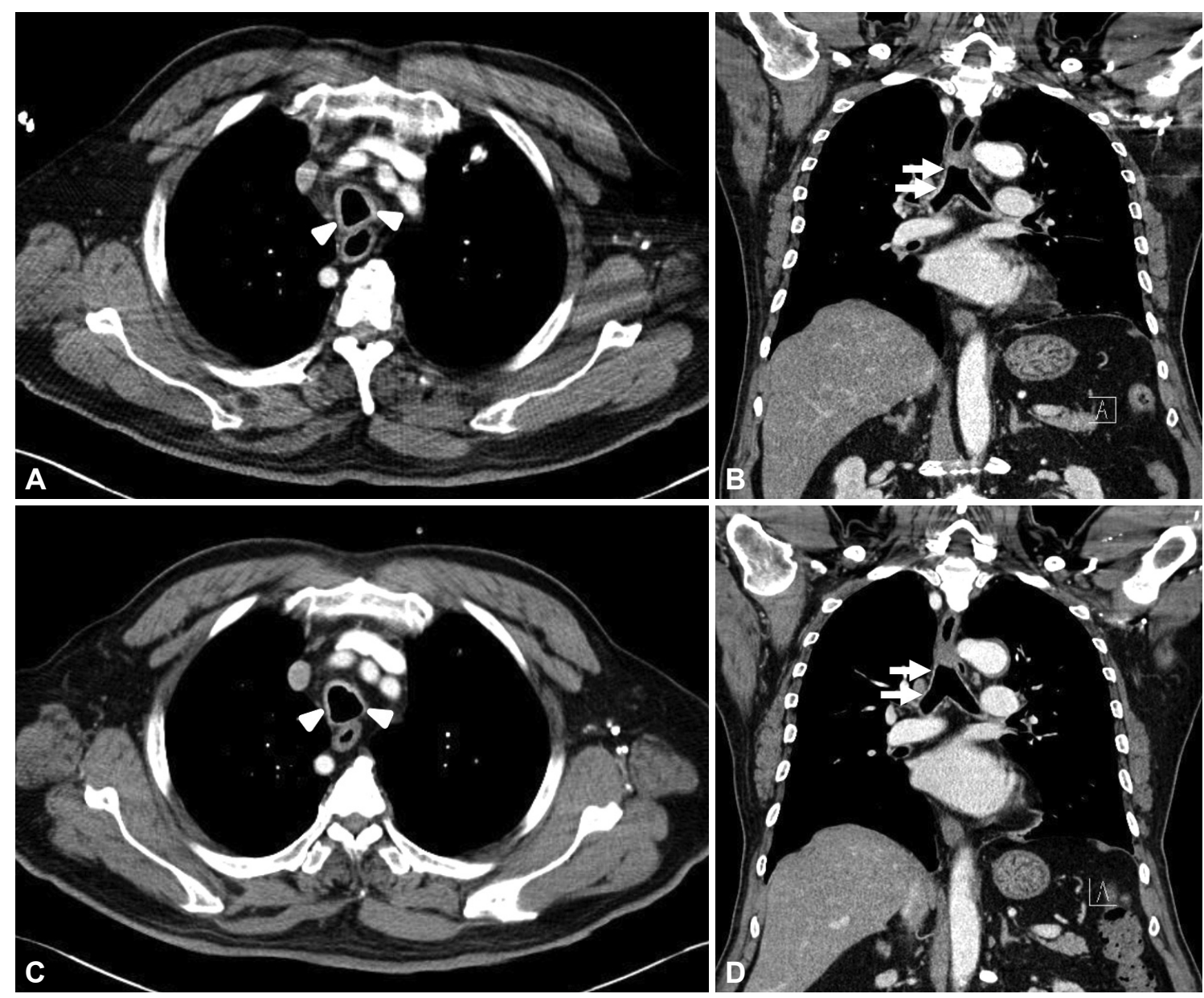

Fig. 2. Axial and coronal CT scans of the chest. In pre-treatment images, they show diffuse relatively enhanced thickened wall of trachea and main bronchus (arrowheads) (A), (arrows) (B). Three months later, they show much decreased enhancement and wall thickening in same sites (arrowheads) (C), (arrows) (D).
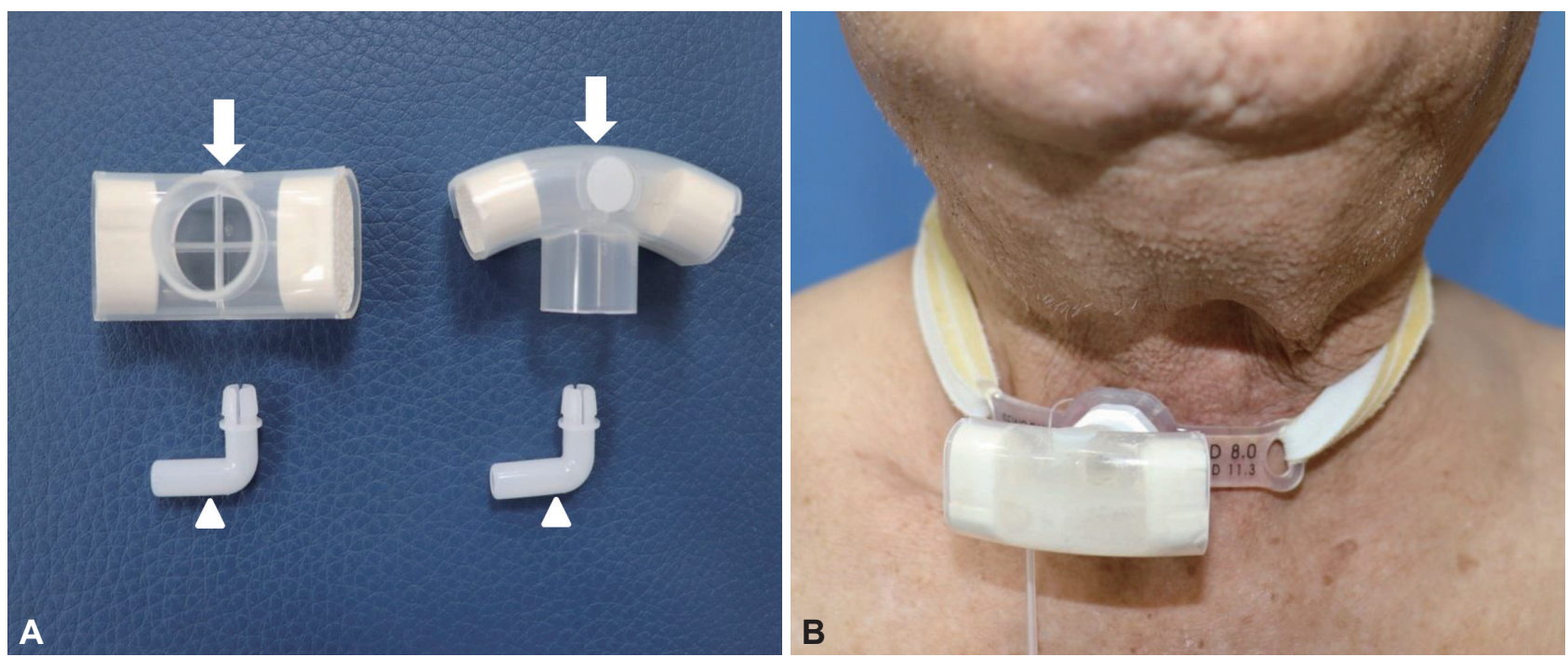

Fig. 3. Tracoe humid assist $I I{ }^{\circledR}$ (Tracoe) is the most commonly used type of heat-moisture exchangers. It consists of main filter (arrows) and oxygen supply port (arrowheads) (A), and applied to the tracheosotomy tube in a total laryngectomized patient (B). 
거의 소실되고, 경한 점막 비후만 관찰되었다(Fig. $1 \mathrm{E}$ and F). 흥부 컴퓨터단층촬영에서도 이전에 비하여 병변 부위의 조 영증강 및 기관벽의 비후가 현저히 감소된 소견이었다(Fig. $2 \mathrm{C}$ and D). 환자는 이후에는 건조증 및 이물감 등을 느끼는 경우에만 간헐적으로 HMEs를 착용하면서 퇴원 8개월이 경 과한 현재까지 기관에 특이 소견 없이 외래 추적 관찰 중이다.

\section{고 찰}

흡입하는 공기는 상기도를 거쳐 하기도에 도달하면 약 $32^{\circ} \mathrm{C}$ 및 상대 습도 $90 \%$ 이상으로 가온 및 가습되고, 폐포에 도달 하면 $37^{\circ} \mathrm{C}$ 및 상대 습도는 $100 \%$ 가 된다. ${ }^{2)}$ 그러나, 장기간 기 관절개관을 유지하거나, 후두전적출술 환자에서는 외부의 차고 건조한 공기가 비강 및 부비동 등을 거치지 않고, 바로 기도로 흡입된다. 이런 상황이 지속되면, 기도점막의 건조, 점 액섬모 청소율의 감소 및 기관상피세포의 손상 등으로 이어 져 기관염, 기관지염 및 폐렴 등의 위험이 증가된다. ${ }^{1,3)}$

들숨의 가온 및 가습 등을 목적으로 하는 열가습 여과기 (HMEs)는 기계환기를 하는 환자에서는 가열 가습기(heated humidifiers)와 비교해서 사강(dead space) 및 기도 저항 등 을 증가시켜, 유용성에 대한 논란이 있으나,') 후두전적출술 환자에서는 상기도 염증 예방 효과에 대해서 유용성이 비교 적 널리 인정되고 있다. ${ }^{2} \mathrm{HMEs}$ 는 날숨에 있는 열과 습기를 여과기에 보관하여, 들숨이 가온 및 가습 등이 되며, 초기에 는 여과기의 크기가 커서 장착이 어려웠으나, 현재는 소형화 되었다. ${ }^{5)}$ 그러나, 여과기 내부에 세균 증식이 일어날 수 있고, 습기와 이물질이 축적될 경우 기도 저항이 증가할 수 있어서, 하루 사용 후 교체가 필수적이다.5) HMEs는 다양한 상품이 있지만, 대부분 여과기가 장착된 본체, 산소 연결관(port) 및 부속품 등으로 구성된다(Fig. 3A). ${ }^{5}$

최근까지 HMEs에 대한 여러 연구가 보고되었다. 2014년에 발표된 연구에서는 HMEs를 사용한 경우가 고식적인 관리만 한 경우보다 연간 8 배의 비용이 더 소요되지만, 감염 및 수면 장애 등의 감소로 삶의 질이 향상된다고 하였다.) 다른 보고 에서는 후두전적출술 환자에서 HMEs를 사용한 군이 미사 용군보다 1.4 배 많은 정상 섬모세포가 관찰되었고, 점액 이동 속도도 유의하게 증가된다고 보고하였다. ${ }^{\prime)}$ 또 다른 연구에서 는 HMEs의 대표적 단점인 여과기 저항에 의한 호흡곤란은 처음 2 주 동안에는 대상 환자의 $43 \%$ 에서 관찰되었으나, 12 주 후에는 $3.4 \%$ 로 현저히 감소하고, 삶의 질도 12 주 후에는 대 부분 크게 향상된다고 하였다. ${ }^{8)}$ 그 외에도 만성폐쇄성 폐질 환을 않고 있는 후두전적출 환자에서 6개월 이상 장기간 적 절하게 HMEs를 사용하면 호기말 양압을 증가시켜 폐포의
허탈을 감소시키고, 기관 내 점막세포의 청소율이 크게 호전 될 수 있다고 알려져 있다.9) 이러한 연구들을 종합하면 후두 전적출 환자에서 $\mathrm{HMEs}$ 를 사용하는 것은 추가 비용이 발생 하고, 사용 초기에 기도 저항 증가로 인하여 순응도가 저하될 수 있으나. 기도 감염의 빈도를 낮추어, 삶의 질을 향상시킨다 고 할 수 있다. 이런 효과를 얻기 위해서는 환자가 HMEs가 발생시키는 기도 저항에 대하여 충분한 자발 호흡이 되는 폐 활량이 필요하며, 반드시 매일 여과기를 교체하고, 환자 또는 보호자가 올바른 방법으로 기관 내 분비물의 흡인하는 것이 중요하다.

본 증례의 치료에 기여한 요인들을 생각해 보면 $\mathrm{HMEs}$ 의 장착, 인공호흡기 적용, 물리적인 가피의 제거, 기관지 내시경 을 통한 생리 식염수 세척, 항생제 투여 및 흡입기 치료 등이 있다. 다른 시술에서는 기관 내부의 건조함이 지속되어 병변 이 계속 재발하였지만, 유일하게 HMEs 적용 24시간 후에 내 시경 소견과 주관적인 증상 등이 현저히 호전되어, 이 기구를 치료에 주된 기여 인자로 생각하게 되었다. 저자들은 본 증례 를 통해서 장기간의 기관절개관 유치 환자 및 후두전적출 환 자 등에서 기도 감염의 예방 및 치료에 HMEs를 이용한 기관 내 가습 및 가온의 향상이 매우 유용하다는 교훈을 얻었다. 이를 모든 후두전적출술 환자에서 적용하는 것은 어렵지만, 기도 점막의 염증이 잘 유발될 수 있는 좁은 기관공, 초고령 환자, 조절되지 않는 당뇨 및 만성 폐쇄성 폐질환 등에서는 예방적 사용을 고려할 수 있다.

결론적으로 저자들이 생각하는 HMEs의 치료적 사용의 가장 좋은 적응증은 기관 점막의 건조 및 가피 등이 보존적 치료에 호전이 없어서 능동적인 가습이 필요한 경우이며, 이 를 통해서 후두전적출 환자의 기도 합병증 예방과 삶의 질 향상에도 도움이 될 수 있다고 생각한다.

중심 단어: 기관염, 후두전적출, 열가습 여과기.

Acknowledgments

None.

Conflicts of Interest

The authors have no financial conflicts of interest.

Authors' Contribution

Conceptualization: Seung Woo Kim. Formal analysis: Beom Mo Koo. Investigation: Beom Mo Koo. Methodology: Seong Kyu Moon. Supervision: Seung Woo Kim. Validation: Seong Kyu Moon. Visualization: Beom Mo Koo. Writing_-original draft: Beom Mo Koo. Writing - review\& editing: Seung Woo Kim. Approval of final manuscript: all authors.

\section{REFERENCES}

1. Brook I. The challenges of treating tracheobronchitis in a laryngectomee due to nontypeable Haemophilus influenzae: a case report. J 
Med Case Rep 2018;12(1):242

2. Inui $\mathrm{D}$, Oto J, Nishimura M. Effect of heat and moisture exchanger (HME) positioning on inspiratory gas humidification. BMC Pulm Med 2006;6:19.

3. Nakanishi N, Oto J, Itagaki T, Nakataki E, Onodera M, Nishimura M. Humidification performance of passive and active humidification devices within a spontaneously breathing tracheostomized cohort. Respir Care 2019;64(2):130-5.

4. Iotti GA, Olivei MC, Braschi A. Mechanical effects of heat-moisture exchangers in ventilated patients. Crit Care 1999;3(5):R77-82.

5. Scheenstra RJ, Muller SH, Vincent A, Ackerstaff AH, Jacobi I, Hilgers FJ. A new heat and moisture exchanger for laryngectomized patients: endotracheal temperature and humidity. Respir Care 2011; 56(5):604-11.
6. Retèl VP, van den Boer C, Steuten LM, Okła S, Hilgers FJ, van den Brekel MW. Cost-effectiveness of heat and moisture exchangers compared to usual care for pulmonary rehabilitation after total laryngectomy in Poland. Eur Arch Otorhinolaryngol 2015;272(9):2381-8.

7. van den Boer C, Muller SH, van der Noort V, Olmos RA, Minni A, Parrilla C, et al. Effects of heat and moisture exchangers on tracheal mucociliary clearance in laryngectomized patients: a multi-center case-control study. Eur Arch Otorhinolaryngol 2015;272(11):3439-50.

8. Macri GF, Bogaardt H, Parrilla C, Minni A, D’Alatri L, de Vincentiis $\mathrm{M}$, et al. Patients' experiences with HMEs and attachments after total laryngectomy. Clin Otolaryngol 2016;41(6):652-9.

9. Palav R, Khode S, Deore N, Datta S, Shah R, Jagade MV, et al. Role of heat moist exchanger in pulmonary rehabilitation after total-laryngectomy. Bombay Hosp J 2011;53(4):735-42. 